\title{
La interpretación intercultural en el Estado constitucional*
}

\section{Intercultural interpretation in the Constitutional State}

SUMARIO

Introducción. I. Sobre el término "interculturalidad". II. Sobre la interculturalidad en materia jurídica. III. Interpretación jurídica como interpretación del derecho. IV. El principio de interpretación intercultural. v. Deliberación judicial y medios dialógicos.

\section{RESUMEN}

El reconocimiento constitucional de los derechos a la identidad cultural y a la justicia indígena ha dado lugar a que se requiera que los tribunales realicen una interpretación intercultural en los casos que involucran a indígenas o a comunidades indígenas. En este artículo se realiza una propuesta sobre la interpretación intercultural de los principios y reglas, teniendo en cuenta que la eficacia de los principios constitucionales mencionados enfrenta grandes barreras como el racismo y la discriminación. De otra parte, se resalta la idea de que la interpretación del derecho en estos casos también plantea problemas morales pues hay que optar por una forma de entender los principios constitucionales en juego.

* Recibido el 18 de noviembre de 2014, aprobado el 11 de febrero de 2015.

Para citar el artículo: R. Villanueva Flores. La interpretación intercultural en el Estado constitucional. Revista Derecho del Estado n. ${ }^{\circ}$ 34, Universidad Externado de Colombia, enerojunio de 2015, pp. 289-310. DOI: 10.18601/01229893.n34.13

** Abogada por la Pontificia Universidad Católica del Perú. Diploma de especialización en Derechos Humanos por el Instituto de Derechos Humanos de la Universidad Complutense de Madrid. Doctora en Derecho por la Universidad de Castilla La Mancha. Profesora Principal de la Facultad de Derecho de la Pontificia Universidad Católica del Perú. Ha sido Viceministra de la Mujer y Defensora Adjunta para los Derechos de la Mujer de la Defensoría del Pueblo del Perú. Ha dirigido la Academia del Ministerio Público y ha tenido a su cargo el Observatorio de Criminalidad de esa institución. Contacto: mrvillan@pucp.edu.pe 
PALABRAS CLAVE

Interculturalidad, interpretación jurídica, interlegalidad, coherencia, Estado constitucional.

\section{ABSTRACT}

The constitutional recognition of the rights to cultural identity and indigenous justice has led to the requirement that courts conduct an intercultural interpretation in cases involving indigenous or indigenous communities. This article presents a proposal on intercultural interpretation of principles and rules, taking into account that the effectiveness of those constitutional principles faces major barriers such as racism and discrimination. However, the idea that law interpretation raises moral problems is also highlighted because in these cases the interpreter has to choose the way in which the constitutional principles involved will be understood.

KEY WORDS

Intercultural, law interpretation, interlegality, coherence, constitutionalism.

\section{INTRODUCCIÓN}

WALSH sitúa en hace menos de dos décadas el momento en que América del Sur empezó a reconocer oficialmente su diversidad ${ }^{1}$. Expresión de este reconocimiento es el hecho de que hoy en día constituciones latinoamericanas consagren el derecho a la identidad cultural o el derecho colectivo a la jurisdicción indígena, estableciendo expresamente, en este último caso, que su límite es el respeto de los derechos fundamentales de la persona. Incluso las constituciones boliviana y ecuatoriana, que son modelo de interculturalidad y decolonialidad ${ }^{2}$, fijan ese límite. Lo propio se advierte en el Convenio 169 de la oit y en la Declaración de las Naciones Unidas sobre los Derechos de los Pueblos Indígenas, esta última alabada por reconocer sistemas colectivos de vida y alejarse del "modelo eurocéntrico moderno-colonial-capitalista"

El reconocimiento de la identidad cultural y de la jurisdicción indígena en los textos constitucionales ha dado lugar a que se reclame de los tribu-

1 C. WALSH. Interculturalidad y (de)colonidad: perspectivas críticas y políticas. Visao Global, 2012, vol 15, núm. 1-2, p. 62.

2 Ibíd.,p. 69.

3 C. WALSh. El pluralismo jurídico: el desafío de la interculturalidad [en línea]. Novamérica.2012, ene-mar, n. ${ }^{\circ} 133$, p. 34. Disponible en: [http://catherine-walsh.blogspot.com/2012/08/ el-pluralismo-juridico-el-desafio-de-la.html] [consulta: 3 noviembre 2014]. 
nales una interpretación plural ${ }^{4}$, intercultural ${ }^{5}$ o "culturalmente sensible" 6 . Aunque esa interpretación no tiene por qué darse solo en el ámbito judicial ${ }^{7}$, no se puede negar la enorme importancia que tienen los jueces en el Estado constitucional y el hecho de que los debates en torno a la identidad cultural y al pluralismo jurídico no han sido ajenos a las altas cortes de justicia. La jurisprudencia de la Corte Constitucional de Colombia demuestra que uno de los problemas que se plantea a raíz del reconocimiento constitucional del derecho a la identidad cultural y de la jurisdicción indígena es el de cómo interpretar el alcance de los derechos fundamentales de los integrantes de las comunidades indígenas. Recientemente, el Tribunal Constitucional Plurinacional de Bolivia, al resolver una demanda de inconstitucionalidad presentada contra varios artículos del Código Penal por vulnerar, principalmente, el derecho de las mujeres a no ser discriminadas, ha señalado que la interculturalidad es una característica del modelo del Estado boliviano y que, dada la diversidad de concepciones -con igual dignidad-respecto de los principios y valores, fines y derechos establecidos en el texto constitucional, deben ser consideradas "en su verdadera dimensión, es decir, conforme a las fuentes de donde emergen las mismas".

Por ello, en este artículo voy a formular una propuesta sobre la interpretación intercultural de principios y reglas en sede judicial, que está pensada principalmente en caso de conflictos internos. En Perú, la Constitución establece que una ley regulará la coordinación entre la justicia ordinaria y la indígena; sin embargo, esa ley no ha sido dictada por el Congreso ${ }^{9}$. No obstante, la justicia ordinaria, tal como ocurre en Colombia, podría conocer,

4 Tribunal Constitucional Plurinacional de Bolivia, sentencia constitucional plurinacional 0206/2014, de 5 de febrero de 2014, párrafo III.8.7. Véase también la sentencia de la Corte Constitucional del Ecuador 113-14-SEP-CC, caso 731-10-EP, de 30 de julio de 2014, amicus curiae.

5 J. M. CASAL. El pluralismo jurídico en América Latina. Algunas reflexiones. Justicia constitucional y derechos fundamentales $n .^{\circ}$ 4, Pluralismo jurídico, V.BAZÁn y C. NASH (editores académicos). Primera edición. Bogotá: Universidad del Rosario, 2014,pp. 80-81. Véase también A. Grijalba. El Estado plurinacional e intercultural en la Constitución ecuatoriana de 2008. En: R. YRIGOYen FAJARdo (editora), Pueblos indígenas. Constituciones y reformas políticas en América Latina. Lima: Instituto Internacional de Derecho y Sociedad, 2010, p. 157.

6 Véase C. NASH Rojas. La interpretación culturalmente sensible de los derechos humanos. Justicia constitucional y derechos fundamentales $\mathrm{n}{ }^{\circ} 4$, cit., pp. 61 y ss.

$7 \quad$ Perú. La Ley 29785, de 7 septiembre de 2011, Ley del derecho a la consulta previa a los pueblos indígenas u originarios, reconocido en el Convenio 169 de la Organización Internacional del Trabajo (orT), regula el principio de interculturalidad según el cual "El proceso de consulta se desarrolla reconociendo, respetando y adaptándose a las diferencias existentes entre las culturas y contribuyendo al reconocimiento y valor de cada una de ellas" (art.4.2).

8 Tribunal Constitucional Plurinacional de Bolivia, sentencia constitucional plurinacional 0206/2014, de 5 de febrero de 2014, párrafo III.4 y III.7.

9 Artículo $149^{\circ}$ de la Constitución peruana. El Acuerdo Plenario 001/2009/CJ-116 de la Corte Suprema ha regulado una inicial coordinación entre la jurisdicción de las rondas campesinas y la jurisdicción penal ordinaria. 
a través del proceso de amparo, las demandas de los integrantes de las comunidades indígenas contra las decisiones de la justicia indígena cuando se alegue la vulneración de derechos fundamentales ${ }^{10}$.

\section{SOBRE EL TÉRMINO "INTERCULTURALIDAD”}

Según WALSh, la palabra “interculturalidad” ingresó al léxico latinoamericano en el campo educativo a principios de los ochentas. Fue en una reunión en México, en 1982, donde se propuso cambiar la expresión "educación bilingüe bicultural" por "educación intercultural bilingüe" tacar es que en la región el uso del término "interculturalidad" fue promovido inicialmente por organismos extranjeros y educadores blanco-mestizos y no por las organizaciones y comunidades indígenas ${ }^{12}$. Hacia fines de los noventas, el discurso indígena ecuatoriano asoció la palabra "interculturalidad" a las materias jurídica, lingüística y de salud ${ }^{13}$. La idea era:

... armonizar o tender un puente comunicacional con la cultura mestiza, es decir, a diferencia del pensamiento fundacional que sólo planteaba acceder a otras culturas para reforzar la propia, aquí se mantiene la tesis anterior, pero se la amplía a la idea de construir una relación de comunicación con las otras sociedades, como esfuerzo de una y otra parte; o la necesidad de la vigencia simultánea de una pluralidad de visiones dentro de un Estado Unitario ${ }^{14}$.

Se trataba de crear un pensamiento intercultural en el que lo indio penetrara a la cultura "blanco-mestiza" y la cultura india incorporara elementos de la otra cultura, para permitir un acercamiento mutuo, su vigencia simultánea y su relación respetuosa. Ello permitiría tender puentes jurídicos, políticos y tecnológicos entre la diversidad ${ }^{15}$. En esa misma época, y en el marco de la reforma de la Constitución de Ecuador de 1998, la interculturalidad era concebida como un eje transversal de la gestión pública, como proceso estratégico para lograr una real integración entre los ecuatorianos sobre la base de un derecho de igualdad social, cultural, política y económica ${ }^{16}$. De acuerdo

10 En el caso de Ecuador se puede presentar un recurso extraordinario de protección ante la Corte Constitucional contra las decisiones de las autoridades indígenas; véanse los artículos $94^{\circ}, 171^{\circ}$ y $437^{\circ}$ de la Constitución ecuatoriana.

11 C. WALSH. Políticas y significados conflictivos [en línea], p. 124. Disponible en: http:// www.nuso.org/upload/articulos/2830_1.pdf [consulta: 3 noviembre 2014].

12 Ibíd. En opinión de esta autora, fue decisiva la influencia de la GTz en Ecuador, Bolivia y Perú.

13 G. RAmón. Nuevos avances en la propuesta del país multicultural [en línea]. Febrero 1998, pp. 5-6. Disponible en: http://alainet.org/active/974\&lang=es [consulta: 3 noviembre 2014].

14 Ibíd., p. 6.

15 Ibíd.,p. 9.

16 C. Walsh. Políticas y significados conflictivos, cit., p. 128. 
con WaLSH, "desde sus comienzos, la interculturalidad ha significado una lucha en la que han estado en permanente disputa asuntos como identificación cultural, derecho y diferencia, autonomía y nación" ${ }^{17}$.

En el siglo xxI, la interculturalidad no se limita al acercamiento y comunicación entre culturas, ni a añadir la diferencia al modelo existente ${ }^{18}$. La interculturalidad se plantea como un "proyecto ético-político de acción transformativa y democracia radical" 19 , que requiere de planes de acción de doble vía, que involucren no solo a los discriminados sino también a los discriminadores ${ }^{20}$. Por otro lado, se advierte de los peligros de adoptar una perspectiva intercultural que sea "funcional" al sistema neoliberal existente, y se propone adoptar una perspectiva crítica ${ }^{21}$. Por ello, TuBINo se refiere a la interculturalidad crítica como una opción societal ${ }^{22}$, que reclama suprimir las causas de la asimetría social y cultural por métodos no violentos ${ }^{23} \mathrm{y}$ crear nuevas formas de modernidad ${ }^{24}$.

El problema central del que se parte no es la diversidad étnico-cultural sino la diferencia construida como patrón de poder colonial, a partir de la raza, que sigue trascendiendo prácticamente todas las esferas de la vida ${ }^{25}$. En consecuencia, se considera que no es suficiente con establecer medidas de acción afirmativa, que ataquen a corto plazo los síntomas de la discriminación y exclusión sistemática, sino que es preciso promover acciones transformativas que aborden las causas de esa discriminación y exclusión para garantizar una convivencia simétrica de largo $\mathrm{plazo}^{26}$. Sin embargo, según Tubino, "no hay que confundir la interculturalidad ni con el llamado nostálgico a un pasado idealizado que nunca existió (la utopía arcaica) ni con el rechazo maniqueo y en bloque a la modernidad occidental. Lo que se rechaza en la modernización es su sesgo homogeneizante y occidentalizador" ${ }^{27}$, el posicionamiento del europeísmo como orden exclusivo de razón, conocimiento

17 Ibíd., p. 125.

18 C. WALSH. Interculturalidad y (de)colonidad: perspectivas críticas y políticas, cit., p. 64.

19 F. Tubino. La interculturalidad crítica como proyecto ético político [en línea]. Ponencia presentada en el Encuentro Continental de Educadores Agustinos, Lima, 24-28 de enero de 2005. Disponible en: https://oala.villanova.edu/congresos/educacion/lima-ponen-02.html [consulta: 3 noviembre 2014]

20 F. Tubino. El interculturalismo frente a los desafíos del pluralismo jurídico. En: Caminos para la Inclusión en la Educación Superior. Santiago: Fundación Equitas, 2006, p.190.

21 F. Tubino. La interculturalidad crítica como proyecto ético político, cit., p. 1.

22 F. Tubino. El interculturalismo frente a los desafíos del pluralismo jurídico, cit., p. 1.

23 F. Tubino. La interculturalidad crítica como proyecto ético político, cit., p. 2.

24 Ibíd.

25 C. WaLSH. Interculturalidad y (de)colonidad: perspectivas críticas y políticas, cit., p. 65 .

26 F. Tubino. El interculturalismo frente a los desafíos del pluralismo jurídico, cit., p. 5.

27 F. Tubino. La interculturalidad crítica como proyecto ético político, cit., p. 2. 
y pensamiento, descartando la relación milenaria entre mundos biofísicos, humanos y espirituales ${ }^{28}$.

Fidel TUBINo distingue la interculturalidad como hecho del interculturalismo como proyecto normativo ${ }^{29}$. Este último supone una relación entre las culturas que busca "las convergencias sobre las cuales establecer vínculos y puntos en común" 30 e impulsa la promoción gradual, desde el Estado y la sociedad civil, de espacios de interacción positiva que permitan el diálogo, el reconocimiento mutuo, el aprendizaje e intercambio así como la cooperación y la convivencia pacífica ${ }^{31}$.

\section{SOBRE LA INTERCULTURALIDAD EN MATERIA JURÍDICA}

También a fines de los noventas, el movimiento indígena de Ecuador defendía que la interculturalidad en materia jurídica implicaba "armonización y coordinación entre derecho indio y derecho nacional y pluralidad jurídica" ${ }^{32}$, respetando tanto los derechos individuales como los colectivos ${ }^{33}$.

Más recientemente, se ha señalado que la diversidad étnico cultural se enfrenta a tres grandes problemas en materia jurídica: a) el monismo legal que reduce el derecho al derecho estatal; b) la oposición jerárquica entre el derecho estatal positivista y el sistema de derecho consuetudinario (un pluralismo jurídico subordinado), y c) la idea de que la interculturalidad es solo un asunto que tiene que ver con el reconocimiento étnico-cultural, y no un problema histórico estructural-racial-colonial que involucra el modelo, estructura y práctica del Estado así como su campo jurídico nacional ${ }^{34}$.

En esa medida, se ha resaltado el esfuerzo de las constituciones ecuatoriana y boliviana por "interculturalizar"; es decir, por resaltar racionalidades y formas de vida históricamente negadas y subordinadas para hacer de ellas piezas clave en la transformación de las sociedad y del Estado ${ }^{35}$. WALSH cita tres ejemplos de este "interculturalizar" en las citadas constituciones: a) la pluralización de la ciencia y el conocimiento, b) los derechos de la naturaleza, y c) el sumak kawsay o buen vivir ${ }^{36}$.

C. WALSH. Interculturalidad y (de)colonidad: perspectivas críticas y políticas, cit., pp.

29 F. Tubino. El interculturalismo frente a los desafíos del pluralismo jurídico, cit. p. 3.

30 C. Giménez Romero. Pluralismo, multiculturalismo e interculturalidad. Propuesta de clarificación y apuntes educativos [en línea] p. 13. Disponible en: [http://red.pucp.edu.pe/ridei/ wp-content/uploads/biblioteca/100416.pdf] [consulta: 3 noviembre 2014]

31 Ibíd.,p. 14.

32 RAmón, G. Nuevos avances en la propuesta del país multicultural, cit., p. 6.

33 Ibíd.,p. 10.

34 C. WALSh. El pluralismo jurídico: el desafío de la interculturalidad, cit., pp. 33-34.

35 C. WALSH. Interculturalidad y (de)colonidad: perspectivas críticas y políticas, cit., p. 69 .

36 Ibíd. 
La interculturalidad en el ámbito jurídico demandaría, además, que la justicia propicie "el análisis de los delitos desde los contextos culturales en los que se cometen, alentando una consideración de las diferencias culturales y una conciliación en torno a ellas y reconociendo las maneras variadas contemporáneas de constituir y vivir en comunidad y colectividad" ${ }^{37}$. La interculturalidad en materia jurídica implicaría no solamente "abrir" el sistema jurídico pluralizándolo, sino repensarlo y refundarlo en su conjunto ${ }^{38}$. En consonancia con lo anteriormente señalado, uno de los requerimientos de la interculturalidad en materia jurídica sería que los sistemas jurídicos reconocieran un pluralismo jurídico no subordinado ${ }^{39}$. A diferencia de quienes defienden el pluralismo jurídico no subordinado, Tubino afirma que los derechos humanos son el referente normativo último del pluralismo jurídico en sentido normativo. Sin embargo, añade que los derechos humanos "precisan permeabilizarse a otras maneras de entenderlos; requieren, en una palabra, tornarse inclusivos de la diversidad"40.

\section{INTERPRETACIÓN JURÍDICA COMO INTERPRETACIÓN DEL DERECHO}

Dado que el objetivo de este artículo es formular una propuesta sobre la "interpretación intercultural" de principios y reglas, resulta obligado realizar una breve referencia a la interpretación jurídica.

Lo primero que hay que señalar es que tanto el término "interpretación" como "interpretación jurídica" son, como dice ATIENZA, términos extraordinariamente ambiguos ${ }^{41}$. En el ámbito del derecho ni siquiera es posible dar una respuesta clara y unívoca sobre los sujetos o el objeto de la interpretación jurídica ${ }^{42}$. Uno de los desacuerdos sobre el objeto de la interpretación se ve reflejado en la distinción entre interpretación de la ley e interpretación del derecho ${ }^{43}$.

37 C. WALSH. El pluralismo jurídico: el desafío de la interculturalidad, cit., p. 37.

38 Ibíd.,p. 35.

39 Ibíd., p. 36. He planteado una opción distinta en R. Villanueva Flores. Constitucionalismo, pluralismo jurídico y derechos de las mujeres indígenas. Revista de Derecho Público n. 32 , junio 2014, Bogotá, Universidad de Los Andes.

40 F. Tubino. El interculturalismo frente a los desafíos del pluralismo jurídico, cit., p. 7.

41 M. AtiEnza. Estado de Derecho, interpretación y argumentación. Anuario de Filosofía del Derecho XIV. 1997, p. 465. Véase también R. GuATINI. Introducción a la teoría de la interpretación. En S. Pozzolo y R. Escudero (eds.), Disposición vs. Norma, primera edición. Lima: Palestra, 2011, pp. 157 y ss.

42 I. LIFANTE VIDAL. Un mapa de problemas sobre la interpretación jurídica. En: I. LIFANTE Vidal (ed.), Interpretación jurídica y teoría del Derecho. Lima: Palestra, 2010, p. 44. Véase también LeTiZia GianFormagGio. Lógica y argumentación en la interpretación jurídica o tomar a los juristas intérpretes en serio, traducción de J. A., Pérez Lledó. Doxa n. ${ }^{\circ}$ 4, 1987, p. 87 y ss.

43 I. Lifante Vidal. Un mapa de problemas sobre la interpretación jurídica, cit., p. 45 y ss. 
En una muy apretada síntesis, se puede afirmar que quienes defienden que lo que se interpreta es la ley sostienen que la interpretación jurídica consiste en atribuir un significado a un documento normativo dado ${ }^{44}$. En cambio, quienes se refieren a la interpretación del derecho sostienen que esta es una actividad más compleja, que no se limita a la atribución de un significado sino que incluye actividades de reconstrucción del derecho (como la ponderación, la resolución de antinomias o la integración de lagunas ${ }^{45}$. DwORKIN incluso afirma que el derecho es una práctica interpretativa, planteando que la práctica jurídica es un ejercicio de interpretación que no solo se da cuando se interpreta una ley sino de manera genera ${ }^{46}$, razón por la cual los abogados no debemos tratar a la interpretación como un problema sui generis sino que debemos estudiarla "como una actividad general, como un modo de conocimiento, atendiendo los otros contextos de dicha actividad" 47.

En este texto, voy a partir de entender que la interpretación intercultural tiene que darse en el marco de la "interpretación del derecho", pues en el Estado constitucional la interpretación no puede limitarse a estipular un significado sino que tiene que realizarse con el objetivo de maximizar los principios constitucionales, lo que puede implicar actividades de reconstrucción del derecho. Según MACCORMICK, la interpretación es una parte de la argumentación jurídica "y sólo puede ser elucidada en el panorama más amplio de la normatividad constitucional y la teoría política, que a su vez pertenecen a la teoría más vasta de la argumentación práctica"48.

Lo que me interesa destacar es que la interpretación no es necesariamente una tarea sencilla y que tiene que estar comprometida con ciertos principios y

44 Véase R. GuATINI. Estudios sobre interpretación jurídica, segunda edición, traducción de Marina Gascón y Miguel Carbonell. México: Editorial Porrúa y Universidad Nacional Autónoma de México, 2000, pp. 3 ss. Ronald Dworkin criticó a la filosofía analítica por considerar que el problema principal era responder a la pregunta ¿qué sentido debe dársele al texto de la ley? Dworkin se refiere a la interpretación del sentido de una obra (o del sistema legal) como un todo (as a whole) y no limitada al significado de una frase específica: véase R. Dworkin. A Matter of Principle, cit., p. 149 y Law's Empire. Cambridge, Mass.: Harvard University Press, 1986, p. 104 y ss.

45 I. Lifante Vidal. Un mapa de problemas sobre la interpretación jurídica, cit., p. 49.

46 R. Dworkin. A Matter of Principle, Cambridge, Mass.: Harvard University Press, 1985, p. 147. Al respecto véase LifANTE VIDAL, I. El Derecho como práctica interpretativa, trabajo realizado en el marco del proyecto de investigación "Argumentación y constitucionalismo" (DER2010-21032), financiado por el Ministerio de Ciencia e Innovación español dentro del subprograma de Proyectos de Investigación Fundamental No Orientada 2010.

47 Dworkin, A Matter of Principle, cit., p. 148. Por eso, este autor afirma que los abogados haríamos bien en estudiar interpretaciones literarias y artísticas. Véase también R. DwORKIN. Justice for Hedgehogs. Cambridge, Mass., y London: Belknap Press of Harvard University Press, 2011, pp. 123 y ss.

48 NeIL MacCormick. Argumentación e interpretación en el Derecho. Doxa n. ${ }^{\circ}$ 33, 2010, p. 66. Robert Alexy señala que la argumentación jurídica es un caso especial de la argumentación práctica (tesis del caso especial): véase R. Alexy, La teoría de la argumentación jurídica. Primera reimpr., Madrid: Centro de Estudios Constitucionales, marzo 1997, pp. 206 y ss. 
propósitos del ordenamiento jurídico ${ }^{49}$. Para ATIENZA, en los casos difíciles la interpretación exige la asunción de una determinada teoría moral, razón por la cual el intérprete tiene que optar por una determinada manera de entender los valores constitucionales ${ }^{50}$. La interpretación no es una tarea neutral, sino que quienes la abordan lo tienen que hacer "previamente equipados con una idea de lo que es valioso en el género pertinente" ${ }^{51}$. Dworkin utiliza el ejemplo de la interpretación de la cláusula que protege la igualdad en la Constitución de los Estados Unidos de Norteamérica, afirmando que no es posible realizar una interpretación útil de la misma que sea independiente de una teoría sobre qué se entiende por igualdad política ${ }^{52}$. En los casos difíciles no se puede evitar recurrir a la "argumentación práctica" pues sin ella no es posible tomar una posición sobre la forma en que se deben entender las instituciones jurídicas ni reflexionar sobre los valores o principios de las sociedades, los Estados y de las comunidades internacionales en que habitamos ${ }^{53}$.

Por lo tanto, no parto de una teoría de la interpretación según la cual dicha actividad consiste "en descubrir el significado objetivo de un texto o la voluntad subjetiva del legislador" 54 , sino más bien de aquella en la que se

49 Dworkin propone un esquema interpretativo de tres etapas: a) La primera es una etapa pre interpretativa en la que se identifican las reglas y normas (estándares) que proporcionan el contenido provisorio de la práctica que, como afirma Lifante, en el caso del derecho serían los materiales prima facie jurídicos; b) La segunda es la etapa interpretativa en la que el intérprete establece una justificación general para los principales elementos de la práctica identificada en la etapa pre interpretativa. Según Lifante, se trata de determinar cuáles son los valores y objetivos que la práctica persigue, y es esta justificación la que constituye para DworkIN el significado o sentido de la práctica; y c) La tercera es la etapa postinterpretativa o reformadora donde el intérprete ajusta su sentido sobre qué necesita "en realidad" la práctica para adecuarse o servir mejor a la justificación que acepta en la etapa interpretativa: véase Dworkin, Law's Empire, cit., p. 65-66, y LiFANTE VIDAL, El Derecho como práctica interpretativa, cit., pp. 13-14.

50 Manuel Atienza. Hermenéutica y filosofía analítica en la interpretación del Derecho. En: I. LifANTE Vidal (editora), Interpretación jurídica y teoría del Derecho, cit., p. 87. Véase también, M. AtiEnza. Las razones del Derecho. Teoría de la argumentación jurídica. Madrid: Centro de Estudios Constitucionales, 1993, p. 249. AtiEnZA sostiene que en los Estados constitucionales hay una conexión intrínseca entre el derecho y la moral pues muchos conceptos básicos, como el de "derechos fundamentales", no pueden comprenderse en términos puramente formales sin acudir a una connotación axiológica, tal como ocurre en el razonamiento justificativo de los jueces: véase M. AtiEnZA. Dos versiones del constitucionalismo. Doxa n..$^{\circ}$ 34, 2011, p. 81.

51 I. Lifante Vidal. El Derecho como práctica interpretativa, p. 7. Sobre la dimensión valorativa en la interpretación del derecho véase C. S. Nino. Derecho, moral y política, Una revisión de la teoría general del Derecho. Barcelona: Ariel, 1994, pp. 95 ss. Véase también la crítica de Dworkin a la distinción entre descripción y valoración que considera ha debilitado a la teoría del derecho: R. Dworkin. A Matter of Principle, cit., p. 148 y ss.

52 R. Dworkin. A Matter of Principle, cit., p. 165. Véase también R. Dworkin. ¿Deben nuestros jueces ser filósofos? ¿Pueden ser filósofos?, trad. Leonardo García Jaramillo. Isonomía n. ${ }^{\circ}$ 32, México, ITAM, abril, 2010, pp. 17 y ss.

53 NeIL MacCormick. Argumentación e interpretación en el Derecho, cit., p. 77.

$54 \mathrm{Al}$ respecto véase MANUEL ATIENZA. Hermenéutica y filosofía analítica en la interpretación del Derecho. En: I. LifanTe Vidal (editora), Interpretación jurídica y teoría del Derecho, 
resalta la importancia de la argumentación, sobre todo en los casos difíciles en los que está en juego la aplicación de principios constitucionales. Como afirma NeIl MACCORMICK, es preciso desplegar argumentos para mostrar razones a favor de la interpretación preferida ${ }^{55}$.

Una idea muy importante estrechamente vinculada con la interpretación del derecho es la de coherencia, especialmente relevante en el Estado constitucional pues los derechos fundamentales de las personas condicionan el contenido y aplicación del resto del ordenamiento jurídico, el mismo que, en varios países de América Latina, incluye a los ordenamientos indígenas.

Es muy conocida la distinción que hace MACCORMICK entre consistencia y coherencia de las normas jurídicas ${ }^{56}$. Para este autor la coherencia en el razonamiento legal es un test importante de su solidez y congruencia (soundness) ${ }^{57}$. La coherencia es el ideal que debe gobernar nuestra perspectiva del sistema jurídico como un sistema, para evitar el salvajismo del caso aislado ${ }^{58}$ o la arbitrariedad ${ }^{59}$; es decir, que una decisión, por ejemplo, sobre cómo interpretar una norma sea tomada por sus propios méritos con respecto a cualquier otra interpretación rival ${ }^{60}$. Más bien, la idea es que la interpretación jurídica esté guiada por los valores, principios o fines a los que sirven las normas legales o que son promovidos por ellas ${ }^{61}$. MACCORMICK no niega que los sistemas jurídicos incluyan una variedad de normas que expresan una pluralidad de principios y opciones políticas; sin embargo, afirma que "son capaces de ser utilizadas de forma tal que se trate de dar tanto sentido como sea posible a

cit. p. 79 y R. Guatini. Fundamentos de una teoría escéptica de la interpretación. En: I. Lifante VIDAL (editora), Interpretación jurídica y teoría del Derecho, cit., p. 154 y ss.

55 NeIL MacCormick. Argumentación e interpretación en el Derecho, cit., p. 69.

56 Hay falta de consistencia cuando las normas son contradictorias. Las decisiones de los jueces (normas particulares) también deben ser consistentes pues no pueden violar el derecho.

57 N. MacCormick. Coherence in Legal Justification. En: A. Pecsenik, L. Lindahl and B. von RoERmund (editors), Theory of Legal Science. Proceedings of the Conference on Legal Science and Philosophy of Science, Synthese Library/Volume 176. Dordrecht, Boston, Lancaster: D. Reidel, 1983, p. 235 y ss. Para MACCoRMICK la coherencia no solo debe presentarse respecto de las normas (coherencia normativa) sino también en relación con los hechos (coherencia narrativa): ibíd, p. 245 y ss.

58 N. MacCormick. Argumentación e interpretación en el Derecho, cit., p. 73.Véase también J. Alonso, Modelos jurídicos de la coherencia. En Racionalidad y Derecho, A. García FigueroA (coordinador). Madrid: Centro de Estudios Políticos y Constitucionales, 2006, pp. 50 y ss.

59 N. MacCormick. Coherence in Legal Justification, cit., p. 237.

60 N. MACCormick. Argumentación e interpretación en el Derecho, cit., p. 73. Nino afirmaba que sin valoraciones de índole moral los materiales jurídicos se presentaban como "cajas negras" absolutamente compatibles con cualquier acción o decisión: Derecho, moral y política. Una revisión de la teoría general del Derecho, cit., p. 100.

61 MacCormick entiende que los fines son estados de cosas que se consideran legítimos, deseables o valiosos. Véase Coherence in Legal Justification, cit, p. 237. Véase también R. Dworkin. La justicia con toga. Traducción de G. Ortiz de Urbina y M. Iglesias Vila. Madrid: Marcial Pons, 2007, pp. 23-24. 
todas en conjunto y tomadas como un todo" ${ }^{62}$. La idea que quiero rescatar es que la interpretación del derecho supone el empleo de los materiales jurídicos de manera coherente con los principios del sistema jurídico.

Según Atienza, los siguientes son algunos rasgos significativos de la noción de coherencia: 1) la coherencia es la consistencia en sentido axiológico, 2) la coherencia es graduable, una decisión o una norma puede ser más o menos coherente, 3 ) el concepto de coherencia es relativo, pues una decisión o norma es coherente en relación a un conjunto de principios y valores ${ }^{63}$.

Se ha señalado que la interculturalidad en el ámbito jurídico implicaría repensar o refundar el derecho en su conjunto. Como he adelantado, mi objetivo es mucho más modesto, pero probablemente más claro, pues se limita a formular una propuesta sobre la interpretación intercultural a cargo de los jueces, en el entendido de que, como afirman postpositivistas como ATIENZA y Ruiz Manero, el derecho no es simplemente una realidad que está dada de antemano sino una actividad en la que el jurista teórico participa y que ha de contribuir a desarrollar ${ }^{64}$.

\section{EL PRINCIPIO DE INTERPRETACIÓN INTERCULTURAL}

Los defensores de la interculturalidad tienen razón en afirmar que en las sociedades postcoloniales la eficacia del reconocimiento constitucional de la pluralidad étnica y jurídica enfrenta grandes barreras como el racismo, la desigualdad y la discriminación, que han llevado a la histórica negación de las formas de vida comunitarias y de los conocimientos considerados "no occidentales". El derecho no ha sido ajeno a esa realidad, que se ha expresado, en el caso peruano, en el procesamiento penal de las autoridades indígenas que administran justicia, a pesar de estar constitucionalmente facultadas para ello, o en la ineficacia del derecho a la consulta de las comunidades indígenas.

$\mathrm{Si}$, como afirma GuASTINI, una de las características de la constitucionalización de los ordenamientos jurídicos es la sobreinterpretación de la Constitución ${ }^{65}$, es posible defender que la interpretación intercultural es un principio implícito, cuya juridicidad "depende de su coherencia valorativa con otras normas del sistema que sí son válidas formalmente" ${ }^{66}$. El principio

62 N. MacCormick. Argumentación e interpretación en el Derecho, cit., p. 73.

63 M. AtIENZA. Sobre "Creación judicial del Derecho de Eugenio Bulygin".En: M. AtIENZA y J. Ruiz Manero. Para una teoría postpositivista del Derecho. Lima-Bogotá: Palestra-Temis, 2009, p. 220.

64 M. Atienza. y J. Ruiz Manero. Dejemos atrás el positivismo jurídico. En: M. Atienza y J. Ruiz Manero. Para una teoría postpositivista del Derecho, cit., p. 152.

65 R. Guatini. La constitucionalización del ordenamiento jurídico: el caso italiano. En: M. Carbonell (editor), Neoconstitucionalismo(s). Madrid: Editorial Trotta, 2003, pp. 53-55.

66 J.Agulló. Positivismo y postpositivismo. Dos paradigmas jurídicos en pocas palabras. En: I. Linfante Vidal (editora), Interpretación jurídica y teoría del Derecho, cit., p. 27. Véase 
de interpretación intercultural es coherente con los principios constitucionales de pluralidad étnica, no discriminación y pluralismo jurídico ${ }^{67}$, y sirve al propósito de lograr una sociedad inclusiva, dentro del reconocimiento de la diferencia ${ }^{68}$. El principio de interpretación intercultural es instrumental a los principios constitucionales anteriormente mencionados ${ }^{69}$. Es pertinente recordar que, en el caso peruano, el Tribunal Constitucional ha señalado:

a) Que el Perú es un Estado poliétnico ${ }^{70}$, en el que el multiculturalismo no es sólo una realidad sino una política estatal ${ }^{71}$;

b) Que los pueblos indígenas crean derecho y que la tolerancia a la diversidad contempla aceptar distintas concepciones de justicia siempre que no contravengan directamente los derechos fundamentales y los fines esenciales del Estado;

c) Que la cultura de los pueblos indígenas tiene el mismo valor y legitimidad que la denominada cultura dominante; y

d) Que el Tribunal Constitucional, en su calidad de supremo intérprete de la Constitución, tiene una función relevante en la tarea de cubrir los vacíos existentes entre las normas y la realidad, y debe estar atento al contexto para repensar categorías jurídicas desde la perspectiva multicultural ${ }^{72}$.

La interpretación intercultural cobra especial relevancia si se tiene en cuenta que el Tribunal Constitucional tiene la última palabra en materia de interpretación de los derechos fundamentales y que, como señala ATIENZA, la razón de ser de la interpretación es la de hacer justicia, logrando el cumplimiento de los principios o valores protegidos por el derecho ${ }^{73}$.

Por lo tanto, en virtud del principio de interpretación intercultural los jueces al aplicar o dotar de contenido a los principios y reglas en casos que afecten a los indígenas o a las propias comunidades, deben considerar elementos de la diversidad cultural como sus cosmovisiones, conocimiento, costumbres,

también M. Atienza. y J. Ruiz Manero. Las piezas del Derecho. Teoría de los enunciados jurídicos. Primera edición. Barcelona: Ariel Derecho, setiembre 1996, p. 24; y R. GuATINI, Estudios de teoría constitucional. Primera reimpresión. Fontamara, México: 2003, p. 137 y ss.

67 En el caso peruano están regulados en los artículos $2 .^{\circ}$, incisos 2) y 19), y $149^{\circ}$ de la Constitución.

68 Véase la sentencia de la Corte Constitucional de Colombia, T-778/05, fundamento 4.5.

69 Guatini, R. Estudios de teoría constitucional, cit., p. 141.

70 Sentencia del Tribunal Constitucional peruano recaída en el expediente 0042-2004-AI/ TC, fundamento 1 .

71 Sentencia del Tribunal Constitucional peruano recaída en el expediente 01126-2011$\mathrm{HC} / \mathrm{TC}$, fundamento 13 .

72 Ibíd., fundamentos 14, 15, 17 y 23.

73 M. Atienza. Dos versiones del constitucionalismo, cit., p. 82. 
normas y procedimientos propios ${ }^{74}$. Se trata de que la interculturlidad opere de ida y vuelta, es decir, no solo de que el derecho estatal (p. ej., los derechos fundamentales) sea tomado en cuenta por las comunidades indígenas, sino de que las normas y prácticas indígenas sean también consideradas por los jueces de la república de los distintos niveles. Esto es especialmente importante en el caso peruano pues la interpretación intercultural se da en los jueces de paz, pero no es nada frecuente que tenga lugar en otras instancias judiciales.

Para que la interpretación intercultural pueda tener lugar es preciso que estas costumbres, normas y procedimientos propios sean coherentes con los principios constitucionales, lo que significa que tienen que ser valorativamente compatibles con ellos ${ }^{75}$. En los casos en los que se interpreta interculturalmente debe desplegarse una intensa actividad deliberativa y justificativa, pues los problemas que plantea el reconocimiento de la identidad cultural o del pluralismo jurídico son también problemas morales dado que, además de los hechos, tienen que ver con la forma en que entendemos los principios constitucionales en juego. En estos casos también se presentan divergencias morales pues las partes en conflicto evalúan de manera diferente "ciertas acciones o comportamientos, o centran su interés en valores distintos"76.

Exigir coherencia valorativa entre las normas o prácticas indígenas y los principios constitucionales no tiene por qué ser necesariamente una exigencia impracticable. Aunque soy consciente de la diversidad de las prácticas indígenas, quiero referirme al término "interlegalidad", que han utilizado desde hace varios años los antropólogos jurídicos para explicar que la "justicia indígena" es una justicia híbrida y mixta ${ }^{77}$. La idea de interlegalidad ha evitado dar una visión pura, aislada y estática de las comunidades indígenas ${ }^{78}$; más bien ha contribuido a dar cuenta de una realidad mucho más matizada ${ }^{79}$.

La justicia indígena es considerada híbrida y mixta porque, por un lado, no se construye de manera separada del sistema jurídico estatal sino que toma de este piezas (leyes, derechos fundamentales), argumentos y actores (policías,

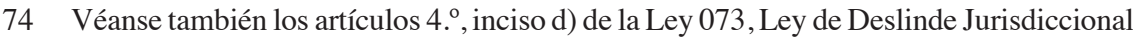
de Bolivia, y $24^{\circ}$ del Código Orgánico de la Función Judicial de Ecuador.

75 J.Agulló. Positivismo y postpositivismo. Dos paradigmas jurídicos en pocas palabras, cit., p. 29.

76 S. Álvarez. Los derechos humanos como valores plurales. Multiculturalismo, cosmopolitismo y conflictos. En: A. Ruzz Miguel (editor), Entre Estado y cosmopolis. Derecho y justicia en un mundo global. Madrid: Editorial Trotta, 2014, p. 191.

77 Véase A. J. Hoekema. Interlegalidad y reconocimiento estatal del derecho y la justicia comunal. En: Pluralismo jurídico e interlegalidad. Textos esenciales, compilación y traducción: A. Guevara Gil y A. Gálvez Rivas. Lima: Pontificia Universidad Católica del Perú, abril 2014, p. 424.

78 Ibíd., p. 428.

79 Emmanuelle Piccoli. El pluralismo jurídico y político a partir del caso de las rondas campesina de Cajamarca. En: FERNANDO García (editor), Identidades, etnicidad y racismo en América Latina, Quito: Colección 50 años FlaCso, 2008, p. 360. 
jueces de paz, tenientes gobernadores); $y$, por el otro, puede recurrir a distintas formas de justicia (indígena o estatal) "en función de la decisión más favorable esperada" $" 80$ de la gravedad del caso. Por ello, Piccoli señala, refiriéndose a lo que sucede entre la justicia de las rondas campesinas de Cajamarca y el sistema estatal, que en la práctica se trata de espacios interjurisdiccionales que permiten pasar de situaciones de coexistencia conflictiva "a situaciones de mixidad más pacíficas y fértiles" ${ }^{\prime 1}$.

Aunque parezca paradójico, la distinción entre valores y normas que realizan tres etnias de los Andes peruanos y ecuatorianos (los quechuas de Cusco y Puno, los campesinos de Cajamarca así como los kichwas de Cotopaxi, Chimborazo y Loja) se asemeja a la distinción entre reglas y principios del postpositivismo, pues para estas etnias los valores dan cuenta de una situación o un comportamiento deseable y sirven como fundamento de las normas, mientras que las normas expresan la expectación de una conducta concreta y se las puede hacer valer mediante coacción y sanciones ${ }^{82}$.

\section{Algunos ejemplos de interpretación intercultural de principios y reglas}

El primer caso al que me quiero referir es el de la interpretación intercultural de los principios constitucionales. En los casos difíciles, el principio interculturalmente interpretado debe interactuar con otros principios constitucionales, lo que planteará la ponderación entre ellos, que es una actividad que forma parte de lo que se conoce como "reconstrucción del derecho".

Utilizaré como ejemplo una controversia resuelta por la Corte Constitucional de Colombia, mediante sentencia T-349/96, a propósito de una demanda de tutela presentada por un indígena emberá chamí en contra de su comunidad, alegando, entre otros, que su derecho al debido proceso había sido violado al haber sido juzgado en la comunidad por los familiares de la víctima. Luego de desarrollar una intensa actividad argumentativa -pues se trataba de un conflicto entre el derecho colectivo de las comunidades indígenas a administrar justicia según sus propias normas y el derecho individual del indígena al debido proceso, entre otros- la Corte Constitucional de Colombia afirmó que la noción de debido proceso debía ser interpretada con amplitud, sin exigir normas e instituciones rigurosamente equivalentes a

80 Emmanuelle Piccoli. Justicia local mixta en Cajamarca (Perú): análisis etnológico de un pluralismo práctico. cuHso Cultura-Hombre-Sociedad [en línea] Julio 2014,p. 62. Disponible en: [http://repositoriodigital.uct.cl:8080/xmlui/bitstream/handle/123456789/1508/Justicia_local_cajamarca.pdf?sequence=3] [consulta: 28 octubre 2014].

81 Ibíd., p. 54. Véase también H. Brandt y R. Franco Valdivia. Normas, procedimientos y valores en la justicia comunitaria. Estudio cualitativo en comunidades indígenas y campesinas de Perú y Ecuador. Lima: Instituto de Defensa Legal, 2007, p. 153.

82 Ibíd., p. 42. Soy consciente de que los investigadores pueden haber hecho una interpretación del significado de los valores y normas en las mencionadas etnias. 
las nuestras, para no distorsionar lo que se propuso el Constituyente al erigir el pluralismo como un principio básico de la Carta ${ }^{83}$. Por ello, señaló que no se violaba el derecho al debido proceso porque, de acuerdo al ordenamiento emberá chamí, el juzgamiento de las infracciones graves correspondía a la comunidad reunida y que, en esas reuniones, se contaba con la presencia de los patrilinajes enfrentados a fin de que el fallo fuera legítimo y no se acabara en una guerra entre familias ${ }^{84}$. La consecuencia de la interpretación intercultural es que al principio del debido proceso se le dotó de un contenido distinto al tradicionalmente asignado ${ }^{85}$, pues de lo contrario no hubiera sido posible considerar constitucional que los parientes de la víctima formaran parte del colectivo de juzgadores de la comunidad.

Sin embargo, es posible que otros principios constitucionales, como el de igualdad entre los sexos, ofrezcan más dificultades para una interpretación intercultural. Como señala ÁLvAREZ, el patriarcado aparece como rasgo común de todas las culturas, aunque se puedan establecer diferencias significativas entre ellas ${ }^{86}$. De acuerdo con las investigaciones en la materia, en las comunidades indígenas existen relaciones desiguales de poder entre hombres y mujeres, una de cuyas expresiones más evidentes es la ausencia de mujeres indígenas en los cargos y espacios de decisión comunitarios ${ }^{87}$. No en vano Brandt y Franco afirman que las mujeres y niños son quienes más se han apropiado del discurso de los derechos y que los hombres son más renuentes a incorporarlo pues sienten que cuestionan su autoridad o el orden establecido en las familias ${ }^{88}$. No conozco de ningún caso en el que alguna mujer indígena, previa controversia en la comunidad, haya exigido, a través de una

83 Corte Constitucional de Colombia, sentencia T-349/96, fundamento 2.4.2.3.

84 Ibíd.

85 Véase Landa Arroyo, C. El debido proceso en la jurisprudencia: Corte Suprema de Justicia de la República del Perú, Tribunal Constitucional del Perú, Corte Interamericana de Derechos Humanos [en línea]. Colección Cuadernos de Análisis de la Jurisprudencia, Volumen 1, Lima: Academia de la Magistratura, diciembre de 2012, p. 108. Disponible en: http://www. amag.edu.pe/wp-content/uploads/2013/05/volumen1.pdf [consulta: 3 noviembre 2014]

86 S. Álvarez. Los derechos humanos como valores plurales. Multiculturalismo, cosmopolitismo y conflictos, cit., p. 196.

87 Véase R. Villanueva Flores. Constitucionalismo, pluralismo jurídico y derechos de las mujeres indígenas, cit., pp. 5-28. Véase también A. J. HoEKEMA, Interlegalidad y reconocimiento estatal del derecho y la justicia comunal, cit., p. 430; T. A. EISENSTADT, Usos y costumbres in postelectoral conflicts in Oaxaca, 1995-2004. An Empirical and Normative Assessment. Latin American Research Review, February 2007, vol 42, n. ${ }^{\circ}$, pp. 61-63; y Voces e historias de mujeres indígenas latinoamericanas. Primera edición. M. SÁNCHEZ NÉSTOR (coord.), México D.F: Unifem-Instituto de Liderazgo Simone de Beauvoir, noviembre de 2005, pp. 25, 44, 52, 55, 64 , $80,82,85$ y 90 .

88 H. Brandt y R. Franco Valdivia. Normas, procedimientos y valores en la justicia comunitaria..., cit., p. 14. Véase también M. T. SiERRA. Mujeres indígenas, justicia y derechos: los retos de una justicia intercultural. Íconos, Revista de Ciencias Sociales, $n .^{\circ} 31$, mayo, 2008 , pp.15-26. 
demanda de amparo, votar en los espacios de decisión de su comunidad. La situación de estas mujeres no es sencilla pues si bien negocian internamente mayores cuotas de poder en la comunidad, parecen enfrentadas al dilema de la defensa de sus derechos individuales o la defensa de los derechos colectivos de la comunidad ${ }^{89}$.

No obstante, si tal demanda judicial se presentara, considero que sería muy difícil que el derecho a la igualdad fuera interpretado interculturalmente en aras de proteger una práctica cultural que excluye a las mujeres de los espacios de poder y decisión, pues dicha práctica no guardaría coherencia con el principio de igualdad. Estaríamos ante un caso de conflicto entre principios constitucionales: por un lado, los derechos colectivos de las comunidades indígenas a la identidad cultural y a aplicar su derecho consuetudinario y, por el otro, el derecho de las mujeres indígenas a no ser discriminadas por ningún motivo.

Aunque pudieran formularse propuestas más o menos coherentes con el principio de igualdad entre los sexos, habría que preferir las más coherentes. Como se ha afirmado anteriormente, la interpretación del derecho supone, en este caso, optar por una determinada manera de entender el derecho a la igualdad entre los sexos. Considero muy difícil que, en aras de armonizar los principios constitucionales en conflicto, un juez de un Estado constitucional pudiera interpretar el derecho a la no discriminación de forma tal que reforzara la situación de exclusión de las mujeres indígenas.

Las reglas también pueden ser interpretadas interculturalmente. Pongo como ejemplo la interpretación de los artículos del Código Penal peruano que regulan la reparación civil en caso de delitos (arts. $152 \mathrm{ss}$ ). Esta es entendida como la restitución del bien, cuando sea posible, o el pago de su valor así como la indemnización por los daños y perjucios. Sin embargo, en el caso citado por PiCCOLI de un enfrentamiento entre familias en un centro poblado, en el que hubo una persona muerta, el Poder Judicial aceptó la reparación civil que no consistía en dinero sino en una decena de cabezas de ganado entregadas a la familia de la víctima ${ }^{90}$. Otro ejemplo de interpretación intercultural de reglas es el que debería realizarse en los Registros Públicos, a fin de que no se rechace la inscripción de los estatutos de las comunidades nativas cuando no especifican el tiempo de duración de la comunidad o las normas relativas a su disolución y destino final de los bienes ${ }^{91}$.

89 Véase Voces e historias de mujeres indígenas latinoamericanas, M. SÁNCHEZ NÉSTOR (coord.), cit.

90 El ejemplo lo he tomado de Piccoli, Justicia local mixta en Cajamarca (Perú): análisis etnológico de un pluralismo práctico, cit., p. 72.

91 A. J. HoEKema. Interlegalidad y reconocimiento estatal del derecho y la justicia comunal, cit., p. 432. El Tribunal Constitucional peruano ha afirmado que los pueblos indígenas, que existieron antes del virreinato y de la República del Perú, mantuvieron sus costumbres e instituciones, o parte de ellas, a pesar de haber sido víctimas de la conquista y de la colonización; 
Un caso en el que no se interpretó interculturalmente la ley, más bien fue inaplicada, es el resuelto por la Corte Constitucional de Colombia en la sentencia T-778/05. Se trataba de una mujer indígena, menor de edad, cuya elección como concejal de Bogotá había sido declarada nula por un tribunal, en aplicación del artículo 27 del Decreto 1421 de 1993, que exigía una edad mínima de 25 años para el cargo, siendo que para el pueblo arhuaco la edad no es el criterio para que una mujer ejerza sus derechos políticos, sino la realización de ciertos ritos vinculados al bautizo y a la menstruación.

El caso de la mujer arhuaca puede ser calificado como el de una laguna axiológica en el nivel de las reglas, pues la norma electoral no consideraba el pluralismo cultural de Colombia como propiedad relevante para establecer los requisitos para el cargo de concejal ${ }^{92}$, a pesar de ser un principio básico recogido expresamente en la Constitución. Para resolver el caso, la Corte Constitucional dejó de aplicar el citado artículo 27 del Decreto 1421, atendiendo a que: a) el derecho a la identidad cultural en el ejercicio del derecho de representación no se encontraba circunscrito a un territorio determinado, b) no se vulneraba un derecho constitucional de mayor peso en el caso concreto, y c) el requisito de edad contemplado en el artículo 27 vulneraba el goce efectivo del derecho a la identidad cultural ${ }^{93}$. Aunque la Corte Constitucional no lo señala de forma expresa, llenó la laguna creando una norma en virtud de la cual, en el caso de los indígenas, los requisitos para ser concejal son los que fijan las costumbres de la comunidad.

\section{DELIBERACIÓN JUDICIAL Y MEDIOS DIALÓGICOS}

Antes me he referido a la actividad deliberativa y justificativa de los jueces al resolver casos difíciles, como el que plantea el reconocimiento constitucional de la pluralidad cultural, resaltando la importancia de la argumentación jurídica en las decisiones judiciales para evitar la arbitrariedad. Sin perjuicio de ello, considero que pensar en formas no ortodoxas de deliberación judicial puede ser también una valiosa herramienta para combatirla ${ }^{94}$. Los jueces pueden promover determinados espacios en los que sean presentados diversos puntos

por ello, su reconocimiento traspasa la dimensión de una mera asociación civil; véase la sentencia recaída en el expediente 01126-2011-HC/TC, fundamentos 19, 22 y 23.

92 Sobre las lagunas axiológicas véase, J. J. Moreso y J. M. Vilajosana. Introducción a la teoría del Derecho. Madrid: Marcial Pons, 2004; M. Atienza. y J. Ruzz Manero. Ilícitos atípicos. Madrid: Editorial Trotta, 2000, pp. 61-62; M. AtIEnZA. Sobre "Creación judicial del Derecho" de Eugenio Bulygin, cit., pp. 213 y ss; así como J. L. Rodríguez. La imagen actual de las lagunas en el derecho. En: ATRIA et al, Lagunas en el derecho. Una controversia sobre el derecho y la función judicial. Madrid: Marcial Pons, 2005, pp. 148 y ss.

93 Corte Constitucional de Colombia, sentencia T-778-05, fundamento 7.

94 Véase R. Gargarella. Un papel renovado para la Corte Suprema. Democracia e interpretación judicial de la Constitución [en línea] pp. 11-12. Disponible en: [http://www.cels.org. ar/common/documentos/gargarella.pdf] [consulta 3 noviembre 2014]; y ROBERTO GARGARELLA 
de vista sobre determinados problemas jurídicos, como ya sucede, en el caso peruano, con el proceso de adopción de los acuerdos plenarios de la Corte Suprema. No obstante, también me quiero referir al establecimiento de lo que GARGARELLA denomina "medios dialógicos"95, ya que son especialmente importantes en las discusiones constitucionales o legales estrechamente vinculadas a problemas estructurales como el racismo, la discriminación y la desigual distribución de los recursos y el poder.

Uno de esos mecanismos podría ser la creación de mesas de diálogo, entre los jueces ordinarios de las distintas jerarquías (que incluyera a las juezas) y las autoridades indígenas, en las que, de manera horizontal e igualitaria, puedan intercambiar conocimientos sobre las formas de resolución de las controversias que se les plantean. La interpretación intercultural se vería facilitada por la creación de estos espacios de interacción positiva entre los jueces y las autoridades indígenas que administran justicia.

Tales espacios posibilitarían un mayor conocimiento mutuo para repensar, cuando fuera posible, las normas y las instituciones de ambos derechos. Pero no solo eso, en el caso peruano, los jueces no gozan de legitimidad, a diferencia de las autoridades indígenas cuya justicia se caracteriza por la proximidad, rapidez y gratuidad ${ }^{96}$. Por ello, un intercambio de ideas sobre la importancia de la legitimidad de la justicia podría resultar sumamente interesante sobre todo para la justicia ordinaria. Otro tema que no debería faltar en estos diálogos es el de la importancia de la participación de las mujeres en la justicia, pues si bien las mujeres indígenas están llevando a cabo negociaciones culturales en el seno de las comunidades, el Estado tiene un papel muy relevante en la promoción de contextos que favorezcan la participación de las mujeres indígenas en la toma de decisiones en el ámbito público, lo que no supone la apelación al derecho penal para conseguirlo ${ }^{97}$.

Según Piccoli, la justicia rondera es "un laboratorio social apasionante, que acepta el desafío del pluralismo, no a través de los textos, sino a través de la práctica" ${ }^{98}$. Nada más compatible con la idea de la interpretación intercultural a cargo de los jueces, en el marco de un concepto postpositivista del derecho, en virtud del cual este no debe ser entendido solo como un conjunto finito de estándares jurídicos sino como una práctica social.

(coordinador), Por una justicia dialógica. El Poder Judicial como promotor de la deliberación democrática. Buenos Aires: Siglo xxI Editores, 2014.

95 R. GaRgarella. Un papel renovado para la Corte Suprema. Democracia e interpretación judicial de la Constitución, cit., p. 12

96 Emmanuelle Piccoli. Justicia local mixta en Cajamarca (Perú): análisis etnológico de un pluralismo práctico, cit., p. 73.

97 Cristina SÁNChez MuÑoz. "Negociaciones culturales y género: hacia un feminismo transnacional”. En: A. Ruiz Miguel. (editor), Entre estado y cosmopolis. Derecho y justicia en un mundo global, cit., pp. 300-301.

98 Ibíd.,p. 73. 


\section{BIBLIOGRAFÍA}

Aguiló, Joser. Positivismo y postpositivismo. Dos paradigmas jurídicos en pocas palabras. En: Isabel Linfante Vidal (editora), Interpretación jurídica y teoría del Derecho, Lima, Palestra, 2010.

Alexy, Robert. La teoría de la argumentación jurídica, primera reimpresión, Centro de Estudios Constitucionales, marzo 1997.

Alonso, Juan Pablo. Modelos jurídicos de la coherencia. En: Alfonso García Figueroa (coord.), Racionalidad y Derecho, Madrid, Centro de Estudios Políticos y Constitucionales, 2006.

Álvarez, Silvina. Los derechos humanos como valores plurales. Multiculturalismo, cosmopolitismo y conflictos. En: Alfonso Ruiz Miguel (editor), Entre estado y cosmopolis. Derecho y justicia en un mundo global, Madrid, Editorial Trotta, 2014.

Atienza, Manuel. Estado de Derecho, interpretación y argumentación, Anuario de Filosofía del Derecho XIV, 1997.

Atienza, Manuel. Las razones del Derecho: teoría de la argumentación jurídica, Madrid, Centro de Estudios Constitucionales, 1993.

Atienza, Manuel. Sobre "Creación judicial del Derecho" de Eugenio Bulygin. En: Manuel Atienza y Juan Ruiz Manero, Para una teoría postpositivista del Derecho, Lima-Bogotá, Palestra-Temis, 2009.

Atienza, Manuel. Hermenéutica y filosofía analítica en la interpretación del Derecho. En: Isabel Linfante Vidal (editora), Interpretación jurídica y teoría del Derecho, Lima, Palestra, 2010.

Atienza, Manuel. Dos versiones del constitucionalismo. En: Doxa n. 34, Alicante, 2011.

Atienza, Manuel y Ruiz Manero, Juan. Las piezas del Derecho: teoría de los enunciados jurídicos, primera edición, Barcelona, setiembre 1996.

Atienza, Manuel y Ruiz Manero, Juan. Ilícitos atípicos, Madrid, Editorial Trotta, 2000.

Atienza, Manuel y Ruiz Manero, Juan. Dejemos atrás el positivismo jurídico. En: Manuel Atienza y Juan Ruiz Manero. Para una teoría postpositivista del Derecho, LimaBogotá, Palestra-Temis, 2009.

Brandt, Hans-Jürgen y Valdivia Franco, Rocío. Normas, procedimientos y valores en la justicia comunitaria. Estudio cualitativo en comunidades indígenas y campesinas de Perú y Ecuador, Lima, Instituto de Defensa Legal, 2007.

Casal, Jesús M. El pluralismo jurídico en América Latina. Algunas reflexiones, Justicia constitucional y derechos fundamentales $n .^{\circ} 4$, Pluralismo jurídico, Bogotá, Editorial Universidad del Rosario, 2014.

Dworkin, Ronald. A Matter of Principle, Cambridge, Massachusetts, Harvard University Press, 1985. 
Dworkin, Ronald. Law's Empire, Cambridge, Massachusetts, Harvard University Press, 1986.

Dworkin, Ronald. La justicia con toga. Traducción de Gimeno Ortiz de Urbina y Marisa Iglesias Vila, Madrid, Marcial Pons, 2007.

Dworkin, Ronald. ¿Deben nuestros jueces ser filósofos? ¿Pueden ser filósofos?, traducción de Leonardo García Jaramillo, Isonomía n. 32, México, ITAM, abril, 2010.

Dworkin, Ronald. Justice for Hedgehogs, Cambridge, Massachusetts, London England, Belknap Press of Harvard University Press, 2011.

Eisenstadt, Todd A. Usos y costumbres in postelectoral conflicts in Oaxaca, 1995-2004. An Empirical and Normative Assessment, Latin American Research Review, vol 42, n. ${ }^{\circ} 1$, February 2007.

Gargarella, Roberto (coord.). Un papel renovado para la Corte Suprema. Democracia e interpretación judicial de la Constitución. Disponible en: http://www.cels.org.ar/ common/documentos/gargarella.pdf

Gargarella, Roberto (coord.). Por una justicia dialógica. El Poder Judicial como promotor de la deliberación democrática, Buenos Aires, Siglo xxi Editores, 2014.

GiANFORMAGgIO, Letizia. Lógica y argumentación en la interpretación jurídica o tomar a los juristas intérpretes en serio, traducción de J. A., Pérez Lledó, Doxa n. ํ 4, Alicante, 1987.

Giménez Romero, Carlos. Pluralismo, multiculturalismo e interculturalidad. Propuesta de clarificación y apuntes educativos. Disponible en: [http://red.pucp.edu.pe/ridei/ wp-content/uploads/biblioteca/100416.pdf]

Grijalba, Agustín. El estado plurinacional e intercultural en la Constitución ecuatoriana de 2008. En: Raquel Yrigoyen Fajardo, Pueblos indigenas: constituciones y reformas políticas en América Latina, (editora), Lima, Instituto Internacional de Derecho y Sociedad, 2010.

GUATINI, RicCARDo. Estudios sobre interpretación jurídica, segunda edición, traducción de Marina Gascón y Miguel Carbonell, México, Editorial Porrúa - Universidad Nacional Autónoma de México, 2000.

GUatini, Riccardo. La constitucionalización del ordenamiento jurídico: el caso italiano. En: Miguel Carbonell (editor), Neoconstitucionalismo(s), Madrid, Editorial Trotta, 2003.

Guatini, Riccardo. Estudios de teoría constitucional, primera reimpresión, México, Fontamara, 2003.

Guatini, Riccardo. Introducción a la teoría de la interpretación. En: Susana Pozzolo y RAFAEl Escudero (editores), Disposición vs. Norma, primera edición, Lima, Palestra, 2011.

Hoenema, André J. Interlegalidad y reconocimiento estatal del derecho y la justicia comunal. En: Pluralismo jurídico e interlegalidad. Textos esenciales, ARMANDO Guevara Gil y Aníbal Gálvez Rivas (editores), Lima, Pontificia Universidad Católica del Perú, abril 2014. 
Landa Arroyo, César. El debido proceso en la jurisprudencia: Corte Suprema de Justicia de la República del Perú, Tribunal Constitucional del Perú, Corte Interamericana de Derechos Humanos, Academia de la Magistratura, Colección Cuadernos de Análisis de la Jurisprudencia, volumen 1, Lima, diciembre de 2012. Disponible en: http://www. amag.edu.pe/wp-content/uploads/2013/05/volumen1.pdf

Lifante Vidal, Isabel. El Derecho como práctica interpretativa. Trabajo realizado en el marco del proyecto de investigación "Argumentación y constitucionalismo" (DER201021032) financiado por el Ministerio de Ciencia e Innovación español dentro del subprograma de Proyectos de Investigación Fundamental No Orientada, 2010.

Lifante Vidal, IsABel. Un mapa de problemas sobre la interpretación jurídica. En: Isabel Lifante Vidal (editora), Interpretación jurídica y teoría del Derecho, Lima, Palestra, 2010 .

MacCormick, Neil. Coherence in legal justification. En: Theory of Legal Science. Proceedings of the Conference on Legal Science and Philosophy of Science, Synthese Library/Volume 176, Alexander Pecsenik, Lars Lindahl, and Bert van Roermund (editors), Dordrecht, Boston, Lancaster, D. Reidel Publishing Company, 1983.

MacCormick, NeIL. Argumentación e interpretación en el Derecho, Doxa n. . 33, Alicante, 2010.

Moreso, José Juan y Vilajosana, Josep María. Introducción a la teoría del Derecho, Madrid, Marcial Pons, 2004.

Nash Rojas, Claudio. La interpretación culturalmente sensible de los derechos humanos, Justicia constitucional y derechos fundamentales $n .^{\circ} 4$, Pluralismo jurídico, Bogotá, Editorial Universidad del Rosario, 2014.

Nino, Carlos Santiago. Derecho, moral y política, Una revisión de la teoría general del Derecho, Barcelona, Ariel, 1994.

Piccoli, Emmanuelle. El pluralismo jurídico y político a partir del caso de las rondas campesina de Cajamarca. En: Fernando García (editor), Identidades, etnicidad y racismo en América Latina, Quito, Colección 50 años Flacso, 2008.

Piccoli, Emmanuelle. Justicia local mixta en Cajamarca (Perú): análisis etnológico de un pluralismo práctico, cuHso. Cultura-Hombre-Sociedad, julio 2014.

Ramón, GaLo. Nuevos avances en la propuesta del país multicultural, febrero 1998. Disponible en: [http://alainet.org/active/974\&lang=es]

Rodríguez, Jorge L. La imagen actual de las lagunas en el derecho. En: Atria, Fernando; Bulygin, Eugenio; Moreso, José Juan; Navarro, Pablo E.; Rodríguez, Jorge L. y Ruiz MANERo, JuAn, Lagunas en el derecho. Una controversia sobre el derecho y la función judicial, Madrid, Marcial Pons, 2005.

SÁnchez Muñoz, Cristina. Negociaciones culturales y género: hacia un feminismo transnacional. En: Alfonso Ruiz Miguel (editor), Entre estado y cosmopolis: derecho y justicia en un mundo global, Madrid, Editorial Trotta, 2014. 
Sánchez Néstor, Martha (coord.). Voces e historias de mujeres indígenas latinoamericanas, México D.F., Unifem-Instituto de Liderazgo Simone de Beauvoir, primera edición, noviembre 2005.

Tubino, Fidel. La interculturalidad crítica como proyecto ético político, Ponencia presentada en el Encuentro Continental de Educadores Agustinos, Lima, 24-28 de enero de 2005. Disponible en: https://oala.villanova.edu/congresos/educacion/lima-ponen-02.html

Tubino, Fidel. El interculturalismo frente a los desafíos del pluralismo jurídico. En: Caminos para la Inclusión en la Educación Superior, Santiago, Fundación Equitas, 2006.

Villanueva Flores, Rocío. Constitucionalismo, pluralismo jurídico y derechos de las mujeres indígenas, Revista de Derecho Público n.³2, Universidad de Los Andes, Bogotá, junio 2014.

Walsh, Catherine. Políticas y significados conflictivos [en línea], p. 124. Disponible en: [http://www.nuso.org/upload/articulos/2830_1.pdf]

Walsh, CATHERINE. Interculturalidad y (de)colonidad: perspectivas críticas y políticas, Visao Global, 2012

Walsh, Catherine. El pluralismo jurídico: el desafío de la interculturalidad [en línea], Novamérica. 2012, ene-mar, n. ${ }^{\circ}$ 133, p. 34. Disponible en: [http://catherine-walsh. blogspot.com/2012/08/el-pluralismo-juridico-el-desafio-de-la.html] 